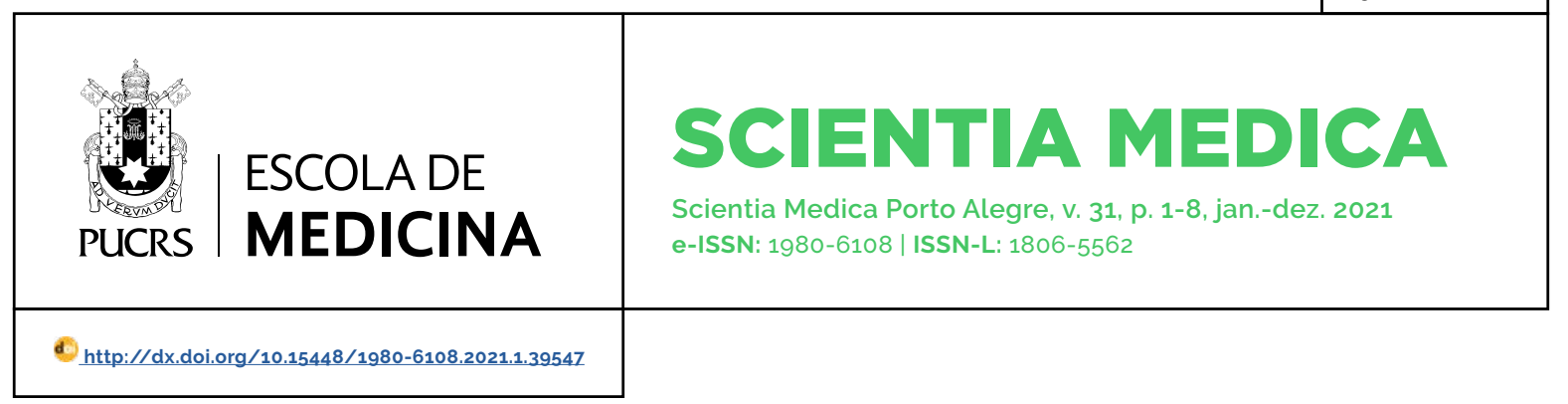

SEÇÃO: EDUCAÇÃO EM CIÊNCIAS DA SAÚDE

\title{
Transição do ensino presencial para o remoto em tempos de COVID-19: perspectiva docente
}

Transition from face-to-face education to online during COVID-19 times: teachers' perspective

Loiane Letícia dos

Santos $^{1}$

orcid.org/000-0003-0571-037

loiane.psicologia@gmail.com

\section{Nathalia de Moraes}

Lebeis Nery ${ }^{1}$

orcid.org/0000-0002-3976-6826

nathalialebeis@yahoo.com.br

\section{Enderson Rodrigues de Carvalho ${ }^{1}$}

orcid.org/0000-0001-8363-2713

enderson.car@gmail.com

\section{Dario Cecilio-}

\section{Fernandes ${ }^{1}$}

orcid.org/0000-0002-8746-1680

dario.fernandes@gmail.com

Recebido em: 17 nov. 2020.

Aprovado em: 2 abr. 2021.

Publicado em: 27 maio. 2021.

\section{Resumo}

Objetivo: este artigo tem como objetivo refletir, a partir do olhar de docentes dos cursos da área da saúde, sobre as estratégias adotadas para a manutenção de suas atividades em meio à pandemia do novo Coronavírus.

Métodos: trata-se de um estudo descritivo do tipo relato de experiência.

Resultados: tais reflexões abordam os avanços e os desafios relacionados ao desenvolvimento docente, as adaptações nas aulas teóricas, teórico-práticas e nos estágios obrigatórios supervisionados e avaliação do aluno no ensino emergencial remoto.

Conclusão: a transição do ensino presencial para o remoto exigiu adaptações e flexibilidade e tais mudanças transformaram o cenário do processo de ensino e aprendizagem, apontando que a tecnologia pode ser ainda mais explorada, tendo perspectivas permanentes.

Palavras-chave: educação a distância, tecnologia, docente, educação médica, pandemia.

\section{Abstract}

Objective: the aim of this study was to reflect, from the perspective of teachers of health courses, on the strategies adopted to maintain their activities during the new Coronavirus pandemic.

Methods: this is a descriptive, experience report.

Results: such reflections addressed the advances and challenges related to teacher development, adaptations in theoretical, theoretical-practical classes and in supervised mandatory internships and student assessment in remote emergency teaching

Conclusion: the transition from face-to-face to remote education required adaptations and flexibility, and these changes transformed the scenario of the teaching and learning process, pointing out that technology can be further explored, with permanent perspectives.

Keywords: online education, technology, teacher, medical education, pandemic.

ABREVIATURAS: IES, Instituições de Ensino Superior; OSCE, Objective Structured Clinical Examination. 


\section{Introdução}

Os primeiros casos de COVID-19 surgiram ainda no mês de dezembro de 2019, na província de Wuhan, na China. Rapidamente, o virus se espalhou ao redor do mundo, trazendo grandes interrupções na vida da população mundial (1). Para conter o avanço dos casos de COVID-19, assim como o número crescente de mortes, diversas medidas de proteção foram orientadas, dentre elas, o isolamento social (2). A vivência em isolamento social resultou no fechamento, por tempo indeterminado, das Instituições de Ensino Superior (IES) e, por conseguinte, na necessidade urgente de adequação de alunos, docentes e profissionais que fazem parte do corpo acadêmico ao ensino emergencial remoto. Tal mudança envolveu a reestruturação de aulas teóricas, teórico-práticas e dos estágios obrigatórios supervisionados.

Mesmo com toda tecnologia disponivel para viabilizar a continuidade das atividades educativas (3), sabemos que há barreiras para elaborar um planejamento pedagógico virtual, anteriormente construído para um processo de ensino/aprendizado presencial. Tais barreiras, especialmente em paises em desenvolvimento, podem ser desde recursos físicos, como a falta de internet de qualidade, de acesso a computadores ou espaços adequados para estudos, até humanos, como a capacitação docente para o uso de tecnologias de ensino remoto (4) uma vez que essas ferramentas ainda são pouco utilizadas por docentes. Ademais, ainda existe a constante desvalorização da carreira docente, que trava uma constante luta por melhores condições de trabalho, salários e investimentos na formação continuada (5).

O planejamento de uma atividade on-line, geralmente, demanda uma organização e um preparo (6), variando entre seis e nove meses (7). No entanto, os docentes tiveram menos de um mês para essa transição. Essas mudanças evidenciam a possibilidade de o docente buscare trazer para a sala de aula e para os momentos de discussão, tecnologias especificas e elementos presenciais de aprendizagem que poderão contribuir com uma formação ainda mais completa e abrangente junto aos estudantes (3).
Com o presente estudo, pretendemos fazer uma reflexão acerca das experiências e das estratégias que estamos adotando para a manutenção de atividades durante a pandemia de COVID-19, a partir do nosso olhar enquanto integrantes da comunidade acadêmica, atuando desde o ensino técnico até a pós-graduação na área da saúde, na condição de pesquisadores, coordenador de curso e gerente de departamentos. A partir dos nossos achados, discutiremos o desenvolvimento docente: avanços e desafios, as mudanças nas estruturas das aulas teóricas, teóricas-práticas e estágios obrigatórios supervisionados, e por fim, a avaliação do aluno no ensino emergencial remoto.

\section{Desenvolvimento docente: avanços e desafios}

A rápida transição do ensino presencial para o ensino emergencial remoto exigiu esforços para a reorganização e a atualização do nosso trabalho, desde a utilização de plataformas on-line até estratégias educacionais. No entanto, o desafio maior foi transformar a cultura de educação, que embora pautada em novos formatos remotos, manteve suas caracteristicas tradicionais, permanecendo com os mesmos moldes das aulas presenciais, com relação ao tempo de aula e os recursos de ensino utilizados. Algo relevante foram as reuniões on-line entre docentes, que por meio da troca e do respeito mútuo, possibilitaram a construção de espaços de reflexão sobre as vivências e as resoluções de problemas encontrados na rotina de ensino, sendo fundamental o auxilio uns dos outros nesse momento para nos reinventarmos (8).

Para medir o sucesso da implantação do ensino remoto emergencial e, também, o envolvimento dos docentes na reorganização de todo esse processo, foi realizado um estudo junto a cursos de graduação em Terapia Ocupacional brasileiros, onde coordenadores de várias regiões do pais, de instituições públicas e privadas, foram convidados a participar e a relatar como estava a situação das atividades e das disciplinas com a modalidade digital em seus cursos. Borba et al. (9) relatam que 
É possivel notar, a partir de algumas respostas discursivas, que docentes das instituições públicas têm presenciado discussões ampliadas e se colocado no debate sobre as propostas de atividades e aulas remotas, ressaltando a importância da participação de docentes na formulação das estratégias que estão sendo criadas, como o acompanhamento de estudantes, criação de comissão de acompanhamento docente, discussões de ações de extensão universitária, mapeamento de estudantes em relação ao acesso às tecnologias digitais e condições socioeconômicas familiares, oportunizando, assim, maiores reflexões sobre as possibilidades da profissão perante o contexto da pandemia. Já para docentes das instituições privadas há uma maior preocupação com o repasse dos conteúdos curriculares, e com isso já estão operando tecnologias e plataformas virtuais para o ensino, em particular às disciplinas com carga horária teórica.

Os impactos das muitas adaptações nos geraram (e a outros colegas), em um primeiro momento, sobrecarga de trabalho, afetando, de certa forma, a saúde mental, além de influenciar na qualidade do trabalho docente, sendo importante a presença de um suporte emocional nesse contexto de pandemia (11). Ainda, assim como diversos docentes, trabalhamos em mais de uma IES, o que acarretou o acúmulo ainda maior de carga de trabalho, por termos que aprender diversos recursos em plataformas distintas, visto que cada instituição adotou uma plataforma diferente.

Apesar da ampla atualização dos docentes, ainda é preciso mobilizar mais reflexões para repensar e discutir os caminhos até então praticados no ensino, bem como em estratégias de sua oferta de forma mais sustentável e inclusiva, garantindo qualidade sem prejuizos nesse momento atípico (10). Apesar das IES em que trabalhamos utilizarem uma plataforma on-line antes da pandemia, a maioria dos professores não fazia uso de tais recursos em sua totalidade, e muito menos como plataforma de ensino, além disso, nem todos os recursos estavam ativados. O sucesso da implantação do ensino remoto emergencial deveu-se ao envolvimento dos professores, ao apoio da IES, além do entendimento por parte dos discentes.
Esta transformação digital na docência, nos levou a quebrar paradigmas, construindo novas diretrizes de ensino e repensando os modelos pedagógicos adotados até então e a sua aplicação (12). O desafio será equilibrar essas práticas on-line aos aspectos que são essenciais à aprendizagem, especialmente, as questões que envolvem o currículo oculto e as experiências práticas, exigindo ainda mais adequação da nossa parte.

\section{Adaptações em aulas teóricas, teóricos- práticas e nos estágios obrigatórios supervisionados}

Com o início das aulas remotas, seria necessário o realinhamento entre os objetivos de aprendizagem, estratégias de ensino e de avaliação. No entanto, observamos em nossa vivência que esse realinhamento não aconteceu, ou quando muito, foi limitado. Ou seja, os objetivos de aprendizagem permaneceram os mesmos e, somente as estratégias de ensino e avaliação se modificaram, mantendo a mesma carga horária das aulas teóricas presenciais, apenas utilizando uma plataforma digital.

$\mathrm{O}$ ensino emergencial remoto permite o uso de tecnologias de comunicação síncronas e assíncronas, sendo que cada uma delas possui suas vantagens e desvantagens. As tecnologias sincronas exigem uma concomitância temporal dos participantes, permitindo a comunicação em qualquer lugar onde estejam, mesmo que não seja necessário o compartilhamento do mesmo espaço. Já a tecnologia assíncrona, permite aos envolvidos determinarem o tempo e o horário de dedicação ao curso, de acordo com a sua disponibilidade, conferindo maior flexibilidade (13). Esses formatos repassam parte da responsabilidade da difusão do conhecimento para o aluno, exigindo que ele seja mais autodidata e seja protagonista do seu aprendizado.

No método síncrono, nós docentes, estamos à disposição dos alunos no horário estipulado, mas, por outro lado, encontramos desafios em nosso espaço privado, como a interferência doméstica, filhos e animais de estimação, além de alguns 
alunos durante as atividades, não possuírem, ou não desejaram abrir a webcam e o microfone. Já na modalidade assíncrona, temos maior flexibilidade para nos organizar, escolhendo o melhor horário a partir da rotina doméstica para construir as atividades de ensino e atender aos alunos em suas dúvidas. Contudo, o desafio é conseguirmos separar quais são os momentos de trabalho e quais são os momentos de vida pessoal (14).

Não foi unânime o método utilizado nas instituições em que atuamos, devido às especificidades de cada uma e, também, ao perfil dos alunos. Algumas decidiram pelo método assíncrono, ou seja, gravar o material, disponibilizar textos e slides, com data para entrega e realização de discussões por meio de fóruns e feedbacks. Essa prática destaca-se pela maior flexibilidade, pois nós docentes e os estudantes pudemos escolher o melhor horário para nos dedicar aos conteúdos, facilitando a organização referente à disponibilidade de tecnologia (organização familiar e número de dispositivos) e internet de qualidade, muitas vezes, com desempenho melhor em horários de menos uso.

Outras IES, por outro lado, optaram pelo método síncrono devido a à interação professor-aluno, que tende a garantir maior comprometimento e envolvimento por meio do vínculo, sendo mais próxima da presencial. Houve, ainda, IES que, em determinados cursos e disciplinas, utilizaram ambas as estratégias, aproveitando das potencialidades de cada uma em um modelo híbrido.

Sabe-se que os cursos da área da saúde possuem um grande volume de aulas teórico-práticas, voltadas para o desenvolvimento de habilidades motoras em laboratórios de habilidades ou simulação com uso de manequins. Essas aulas estão inseridas ao longo do cronograma, com foco no desenvolvimento de conhecimentos, habilidades e atitudes necessárias à prática profissional que antecede o estágio obrigatório supervisionado. Neste momento de pandemia, algumas habilidades não puderam ser treinadas, exigindo de nós docentes, lançar mãos de outras formas de desenvolver essas aulas teórico-práticas, como a produção de vídeos demonstrando as habilidades técnicas e, posteriormente, colocando em discussão com os alunos através de ambientes virtuais de aprendizagem. Também criamos cenários de simulação on-line, por meio de encontros interativos com foco no desenvolvimento de aspectos técnicos relacionados ao raciocínio clínico e ao plano terapêutico, bem como habilidades de comunicação verbal e não verbal (15). Essas ações trazem dinamicidade às aulas, permitindo o desenvolvimento de algumas competências, porém são limitantes para o desenvolvimento de habilidades motoras e atitudes profissionais, que deverão ser treinadas após o retorno das aulas presenciais.

Os estágios obrigatórios supervisionados, que são realizados em hospitais, clínicas, empresas, instituições de longa permanência para idosos, creches, entre outros espaços, também sofreram alterações. Esses ambientes proporcionam aos alunos o desenvolvimento de atividades e de vivências reais, contribuindo também para o desenvolvimento de competências profissionais. Com a suspensão das atividades nesses locais, visando a integridade e bem-estar dos alunos, somado à escassez de equipamentos de proteção individual e à situação atípica nos atendimentos, muitos realizados via telemedicina, nossas instituições tiveram que olhar para os seus espaços de prática para repensar o cenário do estágio. Nesse sentido, foi possivel realizar adaptações, atendendo os próprios funcionários das IES, além do adiantamento de conteúdos teóricos para posterior vivência clínica (16).

Cabe destacar que a não realização dos estágios supervisionados obrigatórios trouxeram desdobramentos para os docentes em diversos âmbitos, a pensar em nossa própria carga horária de trabalho, e possivel diminuição salarial, além de exigir adequação imediata de adiantamento de conteúdos que seriam abordados posteriormente. Outro aspecto é o que diz respeito à reposição desses estágios, em que se cogitam sua realização aos finais de semana, bem como no periodo destinado às férias, alterando o nosso cronograma e influenciando, em algum nível, em nossas vidas pessoais, relacionamentos interpessoais e saúde mental. 


\section{A avaliação do aluno no ensino emergencial remoto}

A avaliação se constitui como um grande desafio para os educadores de forma geral e, quando tratamos do ensino emergencial remoto, ela se torna um desafio ainda maior. Cabe pontuar, que a avaliação necessita ser contínua, para que os alunos acompanhem seu processo de desenvolvimento, além de demandar dos docentes, empatia, sensibilidade e criatividade para propor aos discentes, diversas formas de avaliação (17).

Não podemos esquecer que todo processo avaliativo precisa ter uma finalidade. Neste sentido, podemos destacar a avaliação diagnóstica, formativa e somativa (16). A avaliação diagnóstica é efetuada antes do início da instrução, para averiguar o quanto o aluno já conhece de um determinado assunto. A avaliação formativa regula a aprendizagem dos alunos e ajuda a motivá-los a esforçarem-se no momento adequado. Tem como principais objetivos: verificar o que o aluno dominou de uma determinada tarefa e por meio de feedbacks constante e orientar o aluno a desenvolver a parcela da tarefa em que ainda não houve o dominio. Já a avaliação somativa, pretende avaliar em que medida o aluno se desenvolveu de acordo com o desejado. É frequentemente utilizada ao final de um periodo com o intuito de atribuir notas ou conceitos (18).

Após pensarmos na função ensinada enquanto docentes pudemos escolher a melhor ferramenta para a avaliação. Os métodos de avaliação no ensino remoto foram diversas ferramentas on-line, como a construção de murais colaborativos (por exemplo o Padlet), a criação de formulários de avaliação (Google forms), a formulação conceitos entregues em forma de áudio (como os Podcasts), o uso de aplicativos utilizando a gamificação, que permitiram a elaboração de questionários de diferentes aplicações (como Socrative e Kahoot), o uso das próprias redes sociais digitais para a criação de projetos individuais ou em grupos, entre outras ferramentas.

Apesar de contarmos com diversos métodos de avaliação remota, nos sentimos desafiados ao avaliar os alunos, havendo a preocupação que, pelo modelo atual, a possibilidade do aluno "colar" seria maior, desta forma, houve um repensar de como este processo deveria ser feito. Tradicionalmente, no Brasil, o processo de aprovação ou reprovação do aluno é baseado nas avaliações somativas, algo que no ambiente on-line se tornou muito dificil. Optamos, portanto, pela utilização de diversas ferramentas para avaliações formativas, como os trabalhos em grupos, que se concentraram no domínio do raciocínio clínico, na resolução de problemas e nas habilidades de tomada de decisões. Tal mudança na avaliação nos aproxima à realidade internacional, incorporando os conceitos descritos tanto em sistemas de avaliação $(19,20)$ quanto em avaliação programática $(20,21$, 22). Algumas dessas avaliações e exercícios de avaliação foram feitos até mesmo com consulta ao material de apoio, lembrando que a consulta é algo normal no ato profissional.

Além disso, os modelos mais modernos de avaliação enfatizam o uso de diversas metodologias, além de valorizar o feedback permanente. Apesar do feedback estar presente nas discussões de questões de provas, nos ambientes virtuais de aprendizagem, é possivel obter dados como o número de acessos, as interações realizadas pelos alunos, a participação nas aulas e fóruns. Essas informações nos auxiliam na tomada de decisão referente ao esforço e ao engajamento dos alunos nas atividades, atitudes importantes a serem avaliadas, além do desenvolvimento de conhecimentos relativos à prática profissional. Tais dados podem ser incorporados à prática do feedback, principalmente porque estudos comprovaram que há uma correlação positiva e significativa entre as notas dos alunos nos testes cognitivos e nos exames de Objective Structured Clinical Examination (OSCE) com a sua participação on-line $(23,24)$.

O processo de avaliação faz parte da formação do aluno e sempre dará subsídios para a sua evolução no processo de aprendizado. As avaliações, sejam elas de várias formas e com inovações, auxiliam nosso trabalho e das instituições, e devem continuar sendo aplicadas, autênticas, de maneira confiável, segura e viáveis dentro de um todo (25). Os formatos padrão de avaliação das escolas de medicina é que precisam ser re- 
pensados. Embora algumas dessas estratégias possam ser transitórias enquanto o distanciamento físico for necessário, outras podem se tornar permanentes no programa de avaliação, já que se demonstraram seguras e eficazes. Contudo, as maiores lacunas estão nessa temática, devido ao seu caráter complexo (26).

\section{Conclusão}

A transição do modelo tradicional para o ensino emergencial remoto, em caráter urgente, demandou de nós docentes uma maior adaptação, flexibilidade, disponibilidade de tempo, de energia e de aprendizagem às novas tecnologias e às plataformas existentes. Contudo, isso veio com o custo do desgaste emocional e as dificuldades no processo de adaptação que, muitas vezes, esbarravam no desconhecimento das ferramentas, especialmente, por não terem sido necessárias até então. Portanto, foram enfrentadas barreiras ao desenvolvimento de tais habilidades, especialmente intergeracionais.

Cabe destacar que o cenário de ensino-aprendizagem se transformou de forma considerável, e que fora sim, uma oportunidade única para rever métodos de ensino e repaginar abordagens educacionais. Nesse contexto, admitindo que a tecnologia pode ser associada ao processo de aprendizagem, como já acontece, e ser inserida, especialmente em instituições que não haviam investido nessa modalidade, cenário presente em boa parte das Universidades nacionais. O desafio agora é a preparação das IES para a retomada do ensino presencial, principalmente no que tange às aulas teórico-práticas. As normas governamentais deverão ser seguidas e, também, deveremos contar com a nossa criatividade para a realização de atividades em menores grupos, de forma hibrida, até que a possibilidade da retomada total das aulas teóricas e teórico-práticas se restabeleça.

Acreditamos que o retorno às aulas presenciais não será como antes, já que, docentes, estudantes e as próprias IES mergulharam em um cenário desconfortante no início, mas que após as adaptações, principalmente relacionadas às tecnologias, deixaram claro que elas vieram a somar dentro do ambiente de ensino e de aprendizado. Além de aulas remotas, a tecnologia pode favorecer no incremento de atividades educativas que antes pensávamos apenas para acontecer de forma presencial, como palestras, lives, reuniões pedagógicas e fóruns que se mostraram eficazes por meios digitais.

\section{Notas}

\section{Apoio financeiro}

Esta pesquisa foi parcialmente financiada pela Fundação de Amparo à Pesquisa do Estado de São Paulo (FAPESP), com auxilio à pesquisa regular, número 2020/04909-7, concedido a Dario Cecilio-Fernandes. As opiniões, hipóteses e conclusões ou recomendações expressas neste material são de responsabilidade do autor e não necessariamente refletem a visão da FAPESP.

\section{Declaração de conflito de interesses}

Os autores declaram não haver conflitos de interesses relevantes ao conteúdo deste estudo.

\section{Contribuições dos autores}

Todos os autores fizeram contribuições substanciais para concepção, ou delineamento, ou aquisição, ou análise ou interpretação de dados; e redação do trabalho ou revisão crítica; e aprovação final da versão para publicação.

\section{Disponibilidade dos dados e responsabilidade pelos resultados}

Todos os autores declaram ter tido total acesso aos dados obtidos e assumem completa responsabilidade pela integridade destes resultados.

\section{Referências}

1. World Health Organization. Mental health and psychosocial considerations during the COVID-19 outbreak. Interim guidance. COVID-19: Risk communication and community engagement [Internet]. Geneva. 8 mar 2020. [citado 24 Mar 2021]. Disponivel em: https://www.who.int/publications-detail/WHO-2019-nCoV-MentalHealth-2020.1

2. Faro A, Bahiano MA, Nakano TC, Reis C, Silva BFP, Vitti LS. COVID-19 e saúde mental: a emergência do cuidado. Rev. Estud. Psicol. 2020;37:e200074. https:// doi.org/10.1590/1982-0275202037e200074 
3. Goh OS, Sandars J. A vision of the use of technology in medical education after the COVID-19 pandemic. MedEdPublish. 2020:9(1):49. https://doi.org/10.15694/ mep.2020.000049.1

4. Cecilio-Fernandes D, Parisi MCR, Santos TM, Sandars $\mathrm{J}$. The COVID-19 pandemic and the challenge of using technology for medical education in low and middle income countries. MedEdPublish. 2020;9(1):74. https:// doi.org/10.15694/mep.2021.000074.1

5. Súnega PBC, Guimarães IV. A docência e os desafios da cultura digital. Reflexão e Ação. 2020;25(1):178-97. https://doi.org/10.17058/rea.v25i1.7856

6. Teles G, Soares DMR, de Lima L, Loureiro RC. Docência e tecnologias digitais na formação de professores: planejamento e execução de aulas por licenciandos. Braz. J. Technol. 2020;3(2):73-84. https://doi.org/10.38152/ bjtv3n2-001

7. Hodges CB, Moore S, Lockee BB, Trust T, Bond MA. The difference between emergency remote teaching and online learning. Educase [lnternet] 27 mar. 2020 [citado 28 Mar. 2021]. Disponivel em: https://er.educause. edu/articles/2020/3/the-difference-between-emergency-remote-teaching-and-online-learning

8. Souza APG, Anunciato RMM. Aprendizagens da docência em uma comunidade de aprendizagem online: contribuições da ReAD. RBPAB. 2019;4(12):1090109. http://dx.doi.org/10.31892/rbpab2525-426x.2019. v4.n12.p1090-1109

9. Borba PLO, Bassi BGC, Pereira BP, Vasters GP, Correia RL, Barreiro RG. Desafios "práticos e reflexivos" para os cursos de terapia ocupacional em tempos de pandemia. Cad. Bras. Ter. Ocup. 2020;28(3):1103-15. http://dbx.doi. org/10.4322/2526-8910.ctoen2110

10. Costa R, Lino MM, Souza AIJ, Lorenzini E, Fernandes GCM, Brehmer LCF, et al. Ensino de enfermagem em tempos de COVID-19: como se reinventar nesse contexto? Texto \& Contexto Enfermagem. 2020;29:e20200202. https://doi.org/10.1590/1980-265x-tce-2020-0002-0002

11. Sahu P. University closures due to coronavirus disease 2019 (COVID-19): Impact on education and mental health of students and academic staff. Cureus. 2020;12(4):7541. https://doi.org/10.7759/cureus.7541

12. Basilaia G, Kvavadze D. Transition to online education in schools during a SARS-CoV-2 coronavirus (COVID-19) pandemic in Georgia. Pedagogical Res. 2020;5(4):emoo6o. https://doi.org/10.29333/pr/7937

13. Chaves EOC. Tecnologia na educação, ensino a distância, e aprendizagem mediada pela tecnologia: conceituação básica. Revista de Educação, PUC-Campinas. [Internet]. 1999 [citado 23 Mar 2021] 3(7):29-43. Disponivel em: http://periodicos.puc-campinas.edu.br/ seer/index.php/reveducacao/article/view/421/401

14. Silveira SML, Rossi RA, De Vuono GDD. Pandemia:(mesmos) modos de morar e trabalhar? Revista Políticas Públicas \& Cidades. 2020;1(1)1-5. https://doi. org/10.23900/2359-1552V1n1-5-2020
15. Parisi MCR, Frutuoso L, Benevides SSN, Barreira NHM, Silva JLG, Pereria MC, et al. The challenges and benefits of online teaching about diabetes during the COVID-19 pandemic. Diabetes Metabol Syndr. 2020;14(4):575-6. https://doi.org/10.1016/ j.dsx.2020.04.043

16. Rose S. Medical student education in the time of COVID-19. JAMA. 2020;323(21):2131-2. https://doi. org/10.1001/jama.2020.5227

17. Moreira JA, Henriques S, Barros DMV. Transitando de um ensino remoto emergencial para uma educação digital em rede, em tempos de pandemia. Dialogia. 2020;34:35164. https://doi.org/10.5585/Dialogia.N34.17123

18. Bloom BS, Hastings JT, Madaus GF. Manual de avaliação formativa e somativa do aprendizado escolar. São Paulo: Pioneira;1983. 308 p.

19. Norcini JAM. Consensus framework for good assessment. Med Teach. 2018;40(11):1102-9. https:// doi.org/10.1080/0142159X.2018.1500016

20. Troncon LEA. Efetividade da avaliação programática do estudante de medicina: estudo de caso baseado nas impressões de estudantes e professores de uma escola médica britânica. Rev Bras Educ Méd. 2018;42(3):153-61. https://doi.org/10.1590/ 1981-52712018v42n2rb20170103

21. Van DV, Schuwirth LWT, Driessen EW, Dijkstra J, Tigelaar D, Baartman LKJ, et al. A model for programmatic assessment fit for purpose. Med Teach. 2012;34(3):20514.https://doi.org/10.3109/0142159X.2012.652239

22. Schuwirth LW, Van der Vleuten CP. Programmatic assessment: from assessment of learning to assessment for learning. Med Teach. 2011:33(6):478-85. https:// doi.org/10.3109/0142159X.2011.565828

23. Grangeia TAG, Jorge B, Cecílio-Fernandes D, Tio RA, Carvalho-Filho MA. Learn+Fun! Social media and gamification sum up to foster a community of practice during an emergency medicine rotation. Health Professions Education. 2019:5(4):321-35. https://doi. org/10.1016/j.hpe.2018.11.001

24. Grangeia TAG, Jorge B, Franci D, Santos TM, Setubal MSV, Schweller M, et al. Cognitive load and self-determination theories applied to e-learning: impact on students' participation and academic performance. Plos One. 2016;11(3):e0152462. https://doi.org/10.1371/ journal.pone.0152462

25. General Medical Council. Assessment in undergraduate medical education. [Internet]. United Kingdon: General Medical Council; 2009 Feb [citado 24 Mar. 2021]. Disponivel em: https://www.gmc-uk.org/-/media/ documents/Assessment_in_undergraduate_medical_education___guidance_0815.pdf_56439668.pdf

26. Gordon M, Patricio M, Horne L, Muston A, Alston SR, Pammi M, et al. Developments in medical education in response to the COVID-19 pandemic: A rapid BEME systematic review: BEME Guide No. 63. Med Teach. 2020;42(11):1202-15. https://doi.org/10.1080/ 0142159X.2020.1807484 


\section{Loiane Letícia dos Santos}

Doutoranda em Ensino em Saúde pela Universidade de Campinas (Unicamp), em Campinas, SP, Brasil; professora colaboradora da Faculdade de Medicina de Rio Preto (FAMERP), em São José do Rio Preto, SP, Brasil.

\section{Nathalia de Moraes Lebeis Nery}

Doutoranda em Clínica Médica - Ensino em Saúde pela Universidade Estadual de Campinas (Unicamp), em Campinas, SP, Brasil; professora da Faculdade São Leopoldo Mandic, em Araras, SP, Brasil.

\section{Enderson Rodrigues de Carvalho}

Doutorando no Programa de Clínica Médica - Ensino em Saúde pela Universidade de Campinas (Unicamp), em Campinas, SP, Brasil; coordenador geral de estágios do Centro Universitário Claretiano, em Rio Claro, SP, Brasil.

\section{Dario Cecilio-Fernandes}

Ph.D em Ensino em Saúde pela University of Groningen, Holanda; pesquisador colaborador do Departamento de Psicologia Médica e Psiquiatria da Faculdade de Ciências Médicas, da Universidade Estadual de Campinas (Unicamp), em Campinas, SP, Brasil.

\section{Endereço para correspondência}

Loiane Letícia dos Santos

Universidade Estadual de Campinas

R. Tessália Vieira de Camargo, 126

Cidade Universitária, 13083-887

Campinas, SP, Brasil

Os textos deste artigo foram revisados pela Poá Comunicação e submetidos para validação do(s) autor(es) antes da publicação. 